\title{
POÉTICA E POLÍTICA: RAFAEL ALBERTI, TRADUTOR DE CHARLES BAUDELAIRE
}

\author{
Mayra Moreyra Carvalho 1 \\ ㄴUnniversidade Federal de Juiz de Fora, Juíz de Fora, Minas Gerais, Brasil
}

\begin{abstract}
Resumo: Discutem-se no artigo os aspectos estéticos e políticos da tradução do poeta espanhol Rafael Alberti (1902-1999) para os então denominados Diários íntimos, de Charles Baudelaire, em 1943. Para tanto, considera-se o prólogo escrito por Alberti e a relação entre poetas e poéticas que este gesto tradutório sugere, além do momento em que o texto foi traduzido, que corresponde ao exílio do poeta na Argentina após a Guerra Civil Espanhola.
\end{abstract}

Palavras-chave: Tradução; Exílio; Poesia; Política

\section{POETICS AND POLITICS: RAFAEL ALBERTI TRANSLATES CHARLES BAUDELAIRE}

\begin{abstract}
The article discusses some aesthetical and political aspects of the translation the Spanish poet Rafael Alberti (1902-1999) presents in 1943 for Charles Baudelaire's Journaux intimes. In order to do so, we consider the prologue and the relation between the poets and their poetics suggested by this translation, besides the moment the text was translated, during Alberti's exile in Argentina after the Spanish Civil War.
\end{abstract}

Keywords: Translation; Exile; Poetry; Politics 


\section{Alguns pressupostos}

Em 1943, o poeta espanhol Rafael Alberti (1902-1999) traduziu os então denominados Diários íntimos de Charles Baudelaire ${ }^{1}$. Buscamos refletir sobre esse gesto tradutório considerando que a tradução é uma operação complexa que envolve ideologias, imaginários sobre língua e cultura, convenções literárias, constituição do cânone, mercado editorial (Álvarez and Vidal 1-9), entre outros fatores contextuais e socioculturais (Hermans 25-51). Desse modo, indagamo-nos sobre as implicações políticas e estéticas da tradução albertiana, âmbitos sublinhados pelo poeta-tradutor Daniel Samoilovich:

La traducción es también una herramienta — vamos a decirlo un poco pomposamente- política. [...]

La traducción es también un elemento de lucha en cuanto a que uno va buscando allí el vaciado, el punto de sus propias obsesiones: es un sitio donde uno va modelando su propia poética. (28-29)

Antes de investigar essas facetas da tradução - como ferramenta política e como elemento constitutivo de uma poética - no par Alberti-Baudelaire, convém ter em conta alguns aspectos.

Em 1943, Alberti vivia no exílio, entre temporadas no Uruguai e a residência na Argentina, onde havia chegado em 1940, vindo da França após a derrota republicana ao final da Guerra Civil Espanhola (1936-1939). Seu exílio correspondeu a vinte e três anos na América e quatorze na Itália, itinerário em que o acompanhou a também escritora María Teresa León (1903-1988), sua esposa. Só retornaram à Espanha em 1977, depois da morte de Franco.

\footnotetext{
${ }^{1}$ Embora a crítica baudelairiana problematize a denominação Diários íntimos, em ressalva à ideia de homogeneização que dela resulta (Oliveira 91-94), optamos por ela para evitar o anacronismo, já que assim eram designados no momento em que Alberti os traduz, além de ser o modo como o poeta se refere ao texto.
} 
A essa condição, soma-se a posição política de Alberti, filiado ao Partido Comunista desde a década de 1930. Tal posicionamento repercutiu em seu fazer estético, aguçando, a princípio, a sensibilidade para questões sociais prementes da Espanha dos anos 30. Embora haja composições em tom panfletário, prevalece uma consciência que confronta o problema socio-histórico com o trabalho estético, o que redunda em uma poesia crítico-reflexiva que se interroga sobre sua natureza ante as circunstâncias de um mundo entreguerras. Dessa estirpe são, por exemplo, os poemas escritos durante a Guerra Civil Espanhola de "Capital de la gloria".

Pondere-se também que a tradução se insere no primeiro tempo do Exílio Republicano Espanhol de 1939 (Aznar Soler 9-22). A historiografia desse processo, que significou o êxodo de cerca de meio milhão de espanhóis no imediato pós-guerra (Dreyfus-Armand 29-45), distingue nele três grandes tempos, sendo o primeiro uma mescla de desorientação e esperança, já que, com o fim da Segunda Guerra e a derrota no nazi-fascismo, acreditava-se na deposição de Franco e na restauração da República, respeitando sua legitimidade (Fornerón 16).

No âmbito da poesia, Alberti dará início ao período mais profícuo de sua produção no exílio. Entre 1942 e 1956, compõe, em muitos momentos de maneira simultânea, nove obras em versos, de variada configuração formal, exibindo tanto a elaborada organização de $A$ la pintura (1945-1953), a brevidade das formas populares de Coplas de Juan Panadero (1949-1953), até a criação de uma forma sua, os retornos, de Retornos de lo vivo lejano (1948-1956).

No meio desse verdadeiro canteiro de obras, figuram, além da tradução de Baudelaire, referências ao poeta francês, como em “Arión (Versos sueltos del mar)", de Pleamar (1944), em que Baudelaire é o único poeta-mestre de Alberti não pertencente à tradição ibero-americana:

4

Cantan en mí, maestro mar, metiéndose por largos canales de mis huesos, 
olas tuyas que son olas maestras, vueltas a ti otra vez en un unido, mezclado y sólo mar de mi garganta:

Gil Vicente, Machado, Garcilaso, Baudelaire, Juan Ramón, Rubén Darío, Pedro Espinosa, Góngora... y las fuentes que dan voz a las plazas de mi pueblo. (Alberti 15)

Essa reiterada presença convida-nos a refletir sobre o quanto a convivência que o trabalho de tradução ressoa na escritura do Rafael Alberti exilado. Embora a razão última da escolha dessa tradução permaneça insondável, é possível indagar por que a contundência e a ferocidade dos Diários baudelairianos precisaram ser vertidas ao espanhol naquele "primeiro tempo" do exílio e o que esse gesto pode ter significado na trajetória de um poeta que enfrentava as "condições mais traumáticas de sua vida" (De Marco 44).

Primeiramente, situaremos a tradução de Alberti entre as traduções de Baudelaire para o espanhol e seu trabalho como tradutor. Em seguida, passaremos pelo prólogo e estabeleceremos relações entre a escrita baudelairiana e a poesia rio-platense de Alberti (1940 e 1960).

\section{Breve notícia da tradução de Baudelaire para o espanhol}

Em 1905 se publicam na Espanha as primeiras traduções de $A s$ flores do mal, por Eduardo Marquina, e dos Pequenos poemas em prosa, por Eusebio Heras (Belotto Martínez 150). Quanto aos escritos íntimos baudelairianos, há referências em revistas literárias espanholas, mas não notícia de uma tradução antes da realizada por Rafael Alberti em 1943. Assim, até onde foi possível averiguar, esta pode ter sido a primeira transposição de Journaux intimes para a língua espanhola.

Vale comentar uma tradução posterior, realizada em 1947, pelo poeta catalão Agustí Esclasans i Folch (1985-1967), um católico fervoroso, de orientação política conservadora, que traduzira an- 
teriormente os Pequenos poemas em prosa para o catalão e para o espanhol (Évrard 192-204). Esclasans publicou sob o título de $M i$ corazón al desnudo textos críticos de Baudelaire e a seção correspondente à "Mon cœur mis à nu". No prólogo dessa coletânea, exime Baudelaire de seu tom ácido e crítico e da figura de boêmio, e busca conferir-lhe respeitabilidade e serenidade, destacando sua fé católica e como se distinguia da mediocridade circundante. Essa atitude de Esclasans pode ser entendida como uma maneira de conciliar a evidente oposição de caracteres entre ele e o poeta francês, além de uma tentativa de se legitimar como poeta, tradutor e idealizador de um sistema de regras poético ${ }^{2}$, já que a tradução o inseria no prestigioso âmbito da literatura francesa (Évrard 351-368).

No que tange a outras traduções posteriores a de Alberti, encontramos a de Antonio Martínez Sarrión, Mi corazón al desnudo y otros papeles íntimos (1983), e a de Francisco Torres Monreal, Escritos íntimos (1994). A tradução de Alberti foi reeditada no México em 1979 e na Espanha em 1992.

\section{Situação da tradução albertiana}

Poetas espanhóis contemporâneos de Alberti, entre eles Pedro Salinas, Jorge Guillén, Manuel Altolaguirre, Luis Cernuda, Emilio Prados, Dámaso Alonso e Vicente Aleixandre, foram pródigos em traduções, tendo vertido ao espanhol poemas franceses, ingleses, alemães, italianos e chineses. Rafael Alberti soma-se à nômina, trabalhando a quatro mãos com María Teresa León, como o poeta de sua geração que mais obras em versos traduziu ao espanhol (Munárriz 96).

Em 1932, Alberti verteu as composições de Jules Supervielle (1884-1960) em Bosque sin horas. Em 1957, publicou pela editora Lautaro 3 Poemas (1917-1952), reunião de versos de Paul Éluard traduzidos com María Teresa. No final da década de 1950, apa-

${ }^{2}$ Esclasans idealizou um sistema denominado ritmologia.

${ }^{3}$ Fundada na Argentina em 1942 pela militante comunista Sara Jorge. Teve importante papel na divulgação das obras de Gramsci em língua espanhola (Petra 10-11).

Cad. Trad., Florianópolis, v. 40, $\mathrm{n}^{0}$ 2, p. 153-173, mai-ago, 2020. 
receram suas traduções dos poetas romenos Mihail Eminescu e Tudor Arghezi, além do compêndio Doinas y baladas populares rumanas (1963).

A tradução de Baudelaire foi publicada em 1943 pela editora Bajel, fundada em Buenos Aires em 1942 por dois exilados republicanos espanhóis, Epitafio Madrid e Enrique Naval. A editora pretendia atender outros países hispano-americanos, considerando a expansão da indústria editorial argentina frente à acanhada economia espanhola do Pós-Guerra. Por isso, empenhou-se não só na edição de traduções, mas na distribuição de livros de outras editoras argentinas, permitindo a exportação de cerca de setenta por cento de sua produção durante a década de 1950 (Loedel Rois 266).

A tradução de Rafael Alberti fazia parte da coleção "Diarios íntimos y correspondencias" 4 , entre os quais figurou outra obra organizada e prologada pelo poeta em 1944, Cartas sobre Amarilis, de Lope de Vega (1562-1635).

A notícia dessa editora permite-nos situar o gesto tradutório de Alberti como parte de uma empreitada mercadológica que considerou o potencial público-leitor da tradução entre os diferentes países de língua espanhola. Ademais, não se pode ignorar os contornos mais pragmáticos que a participação de Alberti implicava, pois o poeta sobrevivia de seus textos e eventuais conferências, sempre se debatendo com a escassez de dinheiro ${ }^{5}$.

Com relação aos dois títulos com os quais o poeta participa da coleção, chama atenção a escolha de Lope de Vega e Charles Baudelaire, dois nomes a que ele alude com frequência.

O primeiro é sua referência para o modo de se apropriar da tradição popular da arte que estrutura suas obras dos anos 1920, quan-

${ }^{4}$ Segundo foi possível apurar, outros títulos da coleção foram: Cartas de W. H. Hudson a Cunninghame Graham y a la Sra. de Bontine. 1890-1922 (1942); Cartas a un joven poeta, de Rainer María Rilke, tradução e comentários de Luis Di Lorio e Guillermo Thiele (1943); e Diario íntimo, de Pierre Loti, tradução de Eusebio de Gorbea.

${ }^{5}$ Como menciona em cartas a María Teresa León, em meados de 1940, ou a Cândido Portinari em 05 e 29 de outubro de 1949.

Cad. Trad., Florianópolis, v. 40, no 2, p. 153-173, mai-ago, 2020. 
do se vale da "graça, desvergonha ou ternura" dos versos populares (Alberti 83). A Lope, Alberti dedica duas conferências ${ }^{6}$ entre 1932 e 1935 em que reflete sobre a relação entre a poesia espanhola e o cancioneiro desde a Idade Média até os seus contemporâneos.

A obra organizada para a coleção corresponde às cartas de Lope de Vega à sua última mulher; sobre as quais o prólogo de Alberti obstina-se em despertar interesse: "[...] este epistolario de Lope sobre Amarilis, donde [...], se trasluce aún más con toda desnudez el carnal arrebato, mezcla de humano y de divino, del poeta, en los primeros años de su último delírio" (13).

Já Charles Baudelaire emerge como nota dissonante no ambiente luminoso do primeiro livro de Alberti, Marinero en tierra, de 1925. Do francês, toma-se a epígrafe para o soneto "A Juan Antonio Espinosa, capitán de navío". O verso baudelairiano "Homme libre, toujours tu chériras la mer" sela a fidelidade entre Alberti e o signo de sua predileção, o mar, elemento que congrega seus desejos íntimos e criativos. Entretanto, na epígrafe permanece latente a reflexão dolorosa sobre a perpétua intranquilidade da condição humana que perpassa o poema de Baudelaire, pois o deliberado desígnio de criação de um novo mundo que o soneto de Alberti celebra pode ser lido como índice da atitude do sujeito frente a uma Espanha que começava a experimentar os ares do capitalismo moderno. Nesse sentido, a grande questão baudelairiana sobre o lugar social do poeta e da poesia na modernidade reverbera no poema albertiano "imprimindo-se em negativo" - na expressão de Adorno (68-69) - em uma poesia cujo lirismo é uma reação ao utilitarismo hostil que a circunda.

Já no exílio parisiense, entre 1939 e 1940, Alberti voltará a Baudelaire ao traduzir trechos do texto sobre Victor Hugo aparecido no volume L'art Romantique (1868). Tal atividade contava com um caráter de improviso, pois o poeta começou a aventurar-se nas traduções durante as madrugadas em que trabalhava com María

6 "La poesía popular en la lírica española contemporánea” e "Lope de Vega y la poesía contemporánea”

Cad. Trad., Florianópolis, v. 40, n 2, p. 153-173, mai-ago, 2020. 
Teresa León na rádio Paris-Mundiale, quando eram responsáveis pela leitura de notícias transmitidas a países latino-americanos. Nessas condições, ensaiou a tradução da tragédia Britannicus, de Racine, e de fragmentos de Ovídio e Meleagro, referências que aparecerão nas obras futuramente compostas no exílio, em epígrafes, citações ou no tratamento de questões como a guerra, o amor e o desterro, o que denota o vínculo entre suas escolhas tradutórias e seus interesses e impasses de criação.

Em relação a Baudelaire, trata-se de um poeta com quem Alberti cultiva profunda convivência, como se observa nas aparições do francês na autobiografia albertiana, frequentemente relacionadas a acontecimentos prosaicos:

A veces parto de muy pequeños aeródromos, casi pueblerinos, como algunos que recuerdo, perdidos cerca del mar y casi solitarios, con un enorme cielo encima. Me siento entonces inmensamente posesivo. Todo el azul es mi casa. Mis vestidos, mis huidizos juguetes son las nubes. ¡Oh las nubes, las maravillosas, inolvidables, del gran poema en prosa de Baudelaire! (Alberti 828).

Com efeito, Alberti nunca submeterá Baudelaire ao escrutínio crítico. Sua aproximação tende a ser a do leitor que admira e a do poeta profundamente identificado com o mestre. Valha como exemplo a sobrevivência de seu velho volume de As flores do mal, adquirido em Paris em 1939, que o acompanhou durante todo o exílio:

Lo que ese poemario y su autor representaban para nuestro poeta de por sí se explica al recordar que dicho ejemplar hizo con él la travesía del Mendoza, que le acompañó en América, que de nuevo cruzó de su mano el Atlántico para seguir juntos durante los largos años de Roma y que también asistió a su desexilio para recalar, por fin, en su última biblioteca. (Santonja 34) 


\section{Uma leitura do prólogo}

O prólogo começa com uma breve notícia da obra, lembrando sua história editorial até a publicação em 1887. Informa-se que a edição adotada para a tradução consta das Obras completas de Baudelaire organizadas por Yves-Gérard Le Dantec e publicadas por La Pléiade em 1931 e 1932.

Destacam-se nesse início as escolhas de Alberti para qualificar o texto: "Entre las obras póstumas de Baudelaire, figuran estos dos admirables diarios íntimos: CoHETes y Mi CORAZÓN AL DESNUDO" (9). O adjetivo "admirables" revela a veneração de Alberti pelos diários e predispõe o leitor a fazer o mesmo, na medida em que o sufixo "-able" marca que a coisa de que se fala é merecedora do sentimento que provoca. No segundo parágrafo, encontra-se outro par de adjetivos: "estas desgarradas y luminosas confesiones" (10), em que "desgarradas" refere-se ao despudor e ao potencial de causar compaixão. Quanto ao caráter "luminoso", Alberti justifica-o em seguida, ao defender que esses escritos possibilitam o entendimento profundo de Baudelaire: "No comprende ni puede querer en toda su extensión al poeta de Las Flores del Mal, quien no haya buceado por las azoteas y sótanos de estos diarios íntimos" (10-11).

Adiante, Alberti atribui ao livro duas características: "sinceridade e valentia" (10). A dose de coragem para encarar tanto o teor da escritura como suas consequências é justamente o que Alberti exalta. Ao que parece, o poeta entende que é necessário se investir dessas mesmas "sinceridade" e "valentia" baudelairianas estando ele exilado em decorrência de uma ditadura que tratava de "apagar os rastros" ${ }^{7}$ da arte vinculada à memória dos republicanos. Não por acaso, em dois momentos do prólogo, aproximam-se os tempos da obra e da tradução:

7 Lembramos o conhecido poema de Bertold Brecht, "Apague os rastros" (Gagnebin 52).

Cad. Trad., Florianópolis, v. 40, n 2, p. 153-173, mai-ago, 2020. 
[...] ¡qué buenas bombas todavía para colocar a la puerta de ciertas gentes con las que aún tropezamos!

Época todavía la nuestra de tironazos y patadas, sentimos vivo en nosotros su rechinar de dientes, su salivazo de cada mañana contra el horrible rostro del medio que le había tocado soportar y que le rebajaba hasta hundirlo. (12-13)

Em outra passagem, Alberti afirma que "nada mejor en la literatura universal que estas rápidas, a veces rapidísimas notas para conocer la autobiografía de un alma extraordinária" (10), em que ressalta o aspecto inacabado da obra. Ao invés de sublinhar a incompletude, exalta a brevidade e a concisão como elementos que potencializam o efeito contundente desses escritos.

A designação de autobiografia é outro ponto de interesse, pois, a rigor, o texto de Baudelaire não pertence a tal gênero. Alberti parece evocar um sentido mais amplo. Ao desmembrar o termo "autobiografia", encontramos matizes constitutivos que oferecem uma hipótese para o modo como Alberti o emprega: "1. A ordem do autos ou sujeito (eu); 2. a ordem do byos que nos remete à vida, história; 3. a ordem do graphé ou escritura" (Scarano 5). A análise indica a atuação do sujeito sobre a própria vida pela palavra, e evidencia o processo dinâmico existente na interação desses três vértices: eu-vida-escrita. Complementando essa noção de que a autobiografia seria a construção retrospectiva da vida através da memória atualizada na escritura, encontramos a reflexão de Georges Gusdorf, que reconhece a linguagem como instância mediadora entre o "eu de cá da escritura" e o "eu de lá" nesse exercício que é o "conhecimento de si mesmo" (31-33). Gusdorf ressalva que "as memórias são das autobiografias", mas a "recíproca não parece ser verdadeira” (10), ou não necessariamente, pois lembra a intervenção que o processo da escritura supõe.

A concepção de Alberti se aproxima dessas noções, pois não se atém a uma classificação restrita por gêneros. Antes, apoia-se em uma compreensão que ultrapassa o mero registro das lembranças, 
iluminando um problema que está em jogo nesses Diários, qual seja, "a tensão entre sujeito biográfico e sujeito poético, a impostura, a verdade das máscaras" (Oliveira 57).

A escritura da vida de Baudelaire por Baudelaire - sua autobiografia, portanto - renderá um perfil radicalmente contrastivo, traço tantas vezes apontado pela crítica, ao qual o prólogo também alude. Alberti equipara essa leitura à exploração profunda de terraços e porões. A vertigem, o movimento e a amplitude são atributos que reaparecem concentrados na imagem de contornos dantescos em outra passagem: "Autobiografía de un alma en profundidad, tanto hacia arriba, como hacia abajo: es decir, más allá del séptimo cielo de la luz, de los siete subterráneos de las tinieblas" (Alberti 10), que faz lembrar o poema "Elevação" e seu espírito sulcando alegremente a imensidão profunda ${ }^{8}$. Parece ser mesmo um convite a essa viagem intensa o que o prólogo quer oferecer ao leitor, pois reitera a atração que causam os "calculados claroscuros" desses "pensamientos que se dirían sacados de un pozo a media noche para verterse, de improviso, sobre la espalda tibia de los más tranquilos durmientes" (11), descrição que sublinha o vigor desses escritos.

Essa energia é um elemento pelo qual Alberti tem especial apreço, devido à vitalidade e organicidade que confere ao texto. $\mathrm{O}$ tradutor põe em relevo a raiva e o desespero até a extenuação da luta impotente contra a mediocridade travada por Baudelaire, além de destacar a doçura, a melancolia e a "inefabilidad bajo este caparazón defensivo" (Alberti 11-12).

É precisamente a essa complexidade contrastiva da estética baudelairiana que Alberti adere ao nomear seu sentimento pelo poeta como "un infinito amor" e confessar sua vontade de tomar Baudelaire pela mão e dirigir-lhe o célebre verso de seu "Ao leitor": "meu semelhante, meu irmão" (13). Assim, o poeta-tradutor-leitor abraça a corrosiva e melancólica ironia no poema de As flores do

\footnotetext{
8 "Mon esprit, tu te meus avec agilité,/ Et, comme un bon nageur que se pâme dans l'onde,/Tu sillones gaiment l'immensité profonde/Avec une indicible et mâle volupté" (Baudelaire 136)
}

Cad. Trad., Florianópolis, v. 40, n 2, p. 153-173, mai-ago, 2020. 
mal, reconhecendo-se no incômodo espelho em que a trama desses versos reflete a contraditória natureza humana.

Ao final do prólogo, Alberti se desculpa por possíveis erros e "involuntarias torpezas" na tradução e reitera que "nadie habrá puesto más amor, conciencia y humildad en el traslado al castellano de estas maravillosas páginas" (14).

\section{Ressonâncias baudelairianas}

Em "Situação de Baudelaire", Valéry afirma que "com Baudelaire a poesia francesa ultrapassa finalmente as fronteiras da nação. Ela é lida no mundo inteiro; impõe-se como poesia própria da modernidade; dá origem à imitação, fecunda muitos espíritos" (21). Sem pretender uma exposição exaustiva, trataremos da fecundação do espírito albertiano pelos escritos íntimos de Baudelaire.

Quiçá o fomento maior que a proximidade que a tradução supõe tenha dado à poesia rio-platense de Alberti seja a aparência de um canteiro de obras. Como mencionamos, entre 1940 e 1960, desenvolve-se um dos períodos mais profícuos da produção albertiana. No exílio americano, nove livros escritos em formas poéticas muito distintas perseguem os impasses do homem e do poeta; questões como o compromisso com a memória da Guerra Civil Espanhola e dos companheiros mortos ou exilados; a condição do sujeito desterrado e a denúncia da ditadura espanhola; além do exame em perspectiva da própria obra.

Nessa maneira de trabalhar reverbera o inacabamento dos Journaux baudelairianos. Tal característica se deve também à abreviação da vida do poeta francês, que não teve tempo de finalizar esses escritos. No entanto, referimo-nos ao inacabamento como procedimento estético, assumido como uma possibilidade pelo criador ante a consciência de que a verdade que o habita "é uma substância fluida e irresoluta", de que ele "não é transparente para si mesmo" e que "não cessa de se desmentir" (Gusdorf 30-31). O reconhecimento dessa condição verte-se numa forma inconclusa, 
que responde a uma ética, como Baudelaire expressa ao final de "Fusées": "Creo que he derivado a lo que la gente del oficio llama un hors-d'œuvre. Sin embargo, dejaré así estas páginas porque quiero fechar mi cólera" (49).

O hors-d'œuvre é capaz de datar a cólera e concentra na brevidade uma virulência que a elaboração da obra diluiria. O que o excerto baudelairiano encobre, contudo, é a dose de criação responsável pela aparência inacabada. Trata-se, na verdade, de uma escolha que "evidencia uma preocupação em deslocar qualquer estratégia sentimental implícita na narração romanesca da própria vida" criando uma "retórica da verdade" que "incide sobre afirmações de caráter altamente artificioso" (Siscar 50-51).

Na poesia rio-platense de Alberti, o inacabamento se manifesta na imagem do canteiro de obras no qual o poeta se move, inaugurando várias construções concomitantes. Essa escolha responde a um dilema que pontua todos esses escritos: a pergunta sobre o sentido da poesia estando o poeta dilacerado pelo tempo do exílio. As indagações sobre o ser e sobre a arte são uma só. Por isso, o poema é coxo como o poeta, dizem os versos de "Tirteo", de Pleamar (1944):

Tú eras cojo, Tirteo. Así estos cantos, a los que faltan pies, pero no el alma.

(Alberti 69)

O "idioma de escombros" (Alberti 63) expressa a condição paradoxal do poeta desterrado, entre o reconhecimento da extrema fragilidade de sua matéria-prima e a inclinação a ela como único recurso que lhe resta, ao qual retorna invariavelmente. "Júbilo e tormento", lê-se num poema de Retornos de lo vivo lejano. Essa experiência abismal, segundo Baudelaire - redunda ora na perfeita arquitetura de uma obra como $A$ la pintura, em que o fôlego criador percorre séculos da história da arte; ora no hibridismo tateante da mescla de poesia e prosa de Poemas de Punta del Este (1945-1956). Tanto uma como outra dão conta da urgência da criação em tempos bárbaros. Desse 
modo, encontraremos em "Diario de un día", um Alberti aflito que acorda antes do amanhecer para ganhar, escrevendo, cinco horas de vida (Alberti 281). Uma postura inquieta que revive Baudelaire:

Cuanto más se trabaja, mejor se trabaja y se quiere trabajar más. Cuánto más se produce, se vuelve más fecundo. [...] ¡Cuántos presentimientos y señales enviados ya por Dios advirtiéndome que es tiempo de obrar, de considerar el minuto presente como el más importante de los minutos y hacer mi perpetua voluptuosidad de mi tormento diario, es decir, del Trabajo! (107).

Nessa passagem, encontra-se a palavra de que Alberti aprendeu a gostar a partir do francês: "voluptuosidade" (Alberti 45). Da mesma convivência, quiçá, advenha o gosto do poeta espanhol pelo verso alexandrino, cujas possibilidades confessa ter descoberto justamente em meados da década de 1940, momento em que compõe, em alexandrinos, muitos dos Retornos de lo vivo lejano. Nessa obra, devotada ao exercício da memória, não se pode deixar de ouvir o eco de um dos versos baudelairianos preferidos de Alberti, citado em Poemas de Punta del Este e aludido no prólogo (Alberti 11): "Mère des souvenirs, maîtresse des maîtresses!".

Com efeito, a memória é a faculdade que anima a escritura de Alberti desde sua primeira aparição, articulando-se de modo inseparável à sua concepção de poesia e à exploração estética do seu signo mais caro: o mar. Nascido no litoral sul da Espanha, o andaluz nunca deixará a referência ao cenário da infância, a partir do qual erige sua "mito história pessoal" (Gusdorf 15). Na tríade mar-memória-poesia, entidades habitadas pelo movimento, repousa o modo de ser poeta de Alberti. Daí seu gosto pelo trabalho no canteiro de obras; seu "nomadismo estilístico" (García Montero 50); a necessidade de voltar criticamente à sua poesia primeira, pondo em prática a divisa repetida em várias ocasiões: "A coger los aires!”, o verso medieval desvelado por Lope de Vega. 
A tradução dos Journaux intimes coincide ainda com o momento em que Alberti prepara uma nova edição de seu primeiro livro, Marinero en tierra, na qual trabalhou arduamente entre 1942 e 1945 (Gagen 98). Ratifica-se assim a postura crítica do poeta com relação à própria obra, em especial, com seu livro de estreia, cujas arquitetura e motivos voltam a preocupá-lo no exílio. Esse retorno atesta a vocação de uma poética fundada no movimento, para a qual são insuficientes critérios como a linearidade, a evolução ou a progressão em "fases". Tanto no retrabalho com Marinero en tierra como no longo diálogo entre mar e poeta travado em "Arión, (Versos sueltos del mar)" - "Dale a mi verso, mar, la ligereza,/la gracia de tu ritmo renovado" (15) - reconhecemos uma irmandade com o Baudelaire de "Mon cœur mis à nu":

\begin{abstract}
¿Por qué el espectáculo del mar es tan infinita y eternamente agradable?

Porque el mar ofrece a la vez la idea de la inmensidad y el movimiento. Seis o siete leguas representan para el hombre el radio del infinito. He aquí el infinito diminuto. ¿Qué importa si basta para sugerir la idea del infinito total? Doce o catorce leguas de líquido en movimiento bastan para dar la más alta belleza que puede ofrecérsele al hombre en su habitáculo transitorio (88)
\end{abstract}

Esse elogio do movimento repercute em outra passagem de "Fusées": o arabesco "es el más espiritual de todos los dibujos" (Baudelaire 24); pensamento que fará eco em Alberti na reflexão metapoética de Poemas de Punta del Este:

El arabesco de mi poesía es barroco. La línea recta, escueta, del comienzo, se me curva al instante, complicándoseme en un laberinto de vueltas y revueltas, sin salida aparente. Mas cada guía de esta difícil enredadera es clara, entramando un total de dibujo preciso que concreta lo oscuro, volviéndolo luminoso. (Alberti 280) 
No excerto, o sujeito se situa no entremeio, a zona pouco nítida da trama airosa e melancólica de seu arabesco, entre a escuridão e a claridade, como quem compartilha do espírito baudelairiano que não concebe "un tipo de Belleza donde no haya Dolor" (Baudelaire 32-33). A partir de tal conjunção necessária, também ela uma ética, ajusta-se a lente com a qual um poeta vê o mundo, que lhe permite, segundo Baudelaire, enxergar no espetáculo mais vulgar a manifestação por inteiro da profundidade da vida (35). Fecundado pela "inteligência crítica" e "virtude da poesia" (Valéry 22) de Baudelaire, o espírito de Rafael Alberti, leitor e tradutor, verá num prosaico lobo marinho a condição última do homem desterrado - a solidão do exílio:

\section{EL VIEJO LOBO}

Lejos del rebaño brama viejo y solo.

Garganta antigua del mar, el lobo.

La roca que lo sostiene subió con él desde el fondo.

Lobo y piedra, piedra y lobo.

El primer sol de la tierra ya se le cansa en los ojos.

La ciega luna del mundo, por el ancho lomo. 
Ancianidad de las olas, mugir del viento remoto.

Lo miro. Ya el primer hombre lo miró como yo:

Solo.

(ALBERTI, 2006: 279)

\section{Considerações finais}

A leitura do prólogo de Alberti para sua tradução de Baudelaire e o rastreamento de algumas ressonâncias desses escritos em sua poesia rio-platense permitiram-nos observar que a relação estabelecida entre os dois poetas é, primeiramente, de irmãos de ofício. Não se coloca como problema para Alberti a sistematização do gênero. Há liberdade e familiaridade de sua parte, leitor e poeta muito mais que crítico. Alberti demonstra modéstia diante de um mestre e reclama sua filiação à linhagem inaugurada pelo francês, pois busca compartilhar do espírito agudo, da língua ferina e do olhar perspicaz que não cede a explicações simplificadoras.

Nesse sentido, conectam-se os tempos da escritura dos Journaux e o de sua tradução, retornando à cena a questão do exílio do poeta. O que era um "exílio moral” (García Montero 179) do artista apartado do mundo burguês e de suas convenções no século XIX atualiza-se nos pós-guerras do século XX como inevitabilidade diante da intromissão da História na vida íntima dos sujeitos. No exílio que é fuga por sobrevivência, Alberti não atenua a contundência do texto de Baudelaire; pelo contrário, recupera sua atitude irônica e corrosiva e espera que os artistas da "España Peregrina", expressão cunhada por José Bergamín, se invistam da voz da denúncia, como incitará em "Carta abierta...", de Signos del día: 
¿Qué no podrá el poeta, su pluma delatora, su rauda voz lo mismo que una ametralladora? (Alberti 234)

Desse modo, a escolha da tradução de Baudelaire pelas mãos de um poeta espanhol exilado reveste-se de um caráter ético e político, pois é a uma postura dissonante e aguda que Rafael Alberti quer alinhar sua poesia. Esteticamente, o inacabado ressurge como forma possível para uma literatura compelida a plasmar a experiência da fratura do exílio. De Baudelaire, a poética albertiana busca colher, enfim, a justa mescla de melancolia e doçura, intensidade e inconformismo, sinceridade e valentia.

\section{Referências}

Adorno, Theodor. "Palestra sobre lírica e sociedade". In: Adorno, Theodor. Notas de literatura I. Tradução de Jorge de Almeida. São Paulo: Duas Cidades, Ed. 34, 2008, p. 65-89.

Alberti, Rafael. Poesía III. Ed. Jaime Siles. Barcelona: Seix Barral, 2006.

Alberti, Rafael. "Prólogo". In: Baudelaire, Charles. Diarios intimos. Cohetes. Mi corazón al desnudo. Traducción y prólogo de Rafael Alberti. Buenos Aires: Bajel, 1943, p. 9-14.

Alberti, Rafael. "Prólogo". In: Vega, Lope de. Cartas sobre Amarilis. Último amor. Prólogo y notas de Rafael Alberti. Buenos Aires: Bajel, 1944, p. 8-15.

Alberti, Rafael. "Prosa II". In: Marrast, Robert. Memorias. La arboleda perdida. Barcelona: Seix Barral, 2009. 
Alberti, Rafael. Prosas encontradas. Recopilación y prólogo de Robert Marrast. Barcelona: Seix Barral, 2000.

Álvarez, Román; Vidal, Carmen-África. “Translating: a political act”. In: Álvarez, Román; Vidal, Carmen-África. Translation, power, subversion. Clevedon: Multilingual matters, 1996, p. 1-9.

Aznar Soler, Manuel. "La historia de las literaturas del exilio republicano español de 1939: problemas teóricos y metodológicos”. Migraciones y exilios. Cuadernos de la Asociación para el estudio de los exilios y migraciones ibéricos contemporáneos, $\mathrm{n}^{\mathrm{o}}$. 3, (2002): 9-22. Disponível em: < https://dialnet.unirioja. es/ejemplar/161314 > . Acesso em: 22 de agosto de 2019.

Baudelaire, Charles. As flores do mal. Tradução de Ivan Junqueira. Rio de Janeiro: Nova Fronteira, 2012.

Baudelaire, Charles. Diarios íntimos. Cohetes. Mi corazón al desnudo. Traducción y prólogo de Rafael Alberti. Buenos Aires: Bajel, 1943.

Belloto Martínez, Jesús. La traducción y recepción del poema um prosa um España: Le Spleen de Paris de Charles Baudelaire. 2012. Tese (Tesis doctoral) Departamento de Traducción e Interpretación. Universidad de Alicante, Alicante. Disponível em: < http://rua.ua.es/dspace/handle/10045/33099 > . Acesso em: 22 de agosto de 2019.

De Marco, Valeria. "Rafael Alberti no Prado: da iografiasia às iografias do exílio republicano espanhol de 1939”. In: Jasinsky, Isabel (org.). Literaturas em trânsito, teorias peregrinas. Curitiba: Ed. UFPR, 2015, p. 35-60.

Dreyfus-Armand, Geneviève. "La presencia española um Francia: la profunda huella dejada por los republicanos". Um siglo de inmigración española um Francia. Vigo: Grupo de Comunicación Galicia um el Mundo. (2009): 29-45. Disponível em: < http://www.cronicasdelaemigracion.com/libro/ coleccion-cronicas-de-la-emigracion/un-siglo-de-inmigracion-espanola-enfrancia/20120529151425000292.html > . Acesso em: 22 de agosto de 2019.

Fornerón, Ivan Martucci. Três poetas e três tempos do exílio espanhol de 1939: Luis Cernuda, Emilio Prados e Max Aub. 2015. Tese (Doutorado em Língua 
Espanhola e Literaturas Espanhola e Hispano-Americana) - Faculdade de Filosofia, Letras e Ciências Humanas, Universidade de São Paulo, São Paulo.

Évrard, Anaëlle. Traductions et traducteurs des Petits poèmes em prose de Baudelaire em Espagne. Du modernismo à la Edad de Plata. 2013. Tese (Doctorat de l'Université de Toulouse) - Université Toulouse le Mirail - Toulouse II. Disponível em : <https://tel.archives-ouvertes.fr/tel-01541874/document > Acesso em: 22 de agosto de 2019.

Gagen, Derek. "Marinero um tierra: Alberti's first 'libro orgánico de poemas?"”. The Modern Language Review. Vol. 88, $\mathrm{n}^{\circ}$. 1, (jan. 1993): 91-101.

Gagnebin, Jeanne Marie. Lembrar escrever esquecer. São Paulo, Ed. 34, 2009.

García Montero, Luis. "Alberti, poeta del exilio”. Cuadernos hispanoamericanos. Homenaje a Rafael Alberti. Madrid, ${ }^{\circ}$. 485-486. (Noviembre-Diciembre 1990): 179-188.

García Montero, Luis. Los dueños del vacío. La conciencia poética, entre la identidad y los vínculos. Barcelona: Tusquets, 2006.

Gusdorf, Georges. Lignes de vie I. Les écritures du moi. Paris: Odile Jacob, 1991.

Hermans, Theo. "Norms and the determination of translation. A theoretical framework". In: Álvarez, Román; Vidal, Carmen-África. Translation, power, subversion. Clevedon: Multilingual matters, 1996, p. 25-51.

Loedel Rois, Germán. Los traductores del exilio republicano español um Argentina. Barcelona, 2012. Tesi doctoral - Departament de traducció - Ciències del llenguatge, Universitat Pompeu Fabra.

Munárriz, Jesús. "La traducciones poéticas del27". Cuadernos hispanoamericanos, $\mathrm{n}^{\mathrm{o}}$. 697-698. (julio-agosto 2008): 57-103.

Oliveira, Thiago Mattos de. (Re)traduções brasileiras de Mon coeur mis à nu, de Charles Baudelaire. 2015. Dissertação (Mestrado em Língua e Literatura 
Francesa) - Faculdade de Filosofia, Letras e Ciências Humanas, Universidade de São Paulo, São Paulo.

Petra, Adriana. "El momento peninsular. La cultura italiana de posguerra y los intelectuales comunistas argentinos". Revista IZQUIERDAS, año 3, número 8, (2010): 1-25. Disponível em: < https://dialnet.unirioja.es/servlet/ articulo? codigo $=3394257>$. Acesso em: 22 de agosto de 2019 .

Samoilovich, Daniel. “'Esta cosita que hablamos nosotros” o las razones por que um poeta traduce. Caracol. $n^{\circ}$. 5, (2013): 18-33. Disponível em: <https://www. revistas.usp.br/caracol/article/view/69239/71701 > . Acesso em: 22 de agosto de 2019.

Scarano, Laura. "El sujeto autobiográfico y su diáspora: protocolos de lectura". Orbis Tertius, 2(4), (1997): 1-10. Disponível em: < http://www.orbistertius.unlp. edu.ar/article/view/OTv02n04a11/4008 > . Acesso em: 22 de agosto de 2019.

Siscar, Marcos. Poesia e crise: ensaios sobre a "crise da poesia" como topos da modernidade. Campinas: Editora da Unicamp, 2010.

Valéry, Paul. "Situação de Baudelaire". In: Valéry, Paul. Variedades. Tradução de Maiza Martins de Siqueira. São Paulo: Iluminuras, 2007, p. 21-31.

Recebido em: 20/12/2019

Aceito em: 26/03/2020

Publicado em maio de 2020

Mayra Moreyra Carvalho. E-mail: mayramoreyra@gmail.com. ORCID: https:// orcid.org/0000-0002-1580-3346. 